\title{
USO DE LODO SÉPTICO PARA A PRODUÇÃO DE ROSAS
}

\begin{abstract}
Beatriz A. Almeida (Em), Jessica R. Silva (Em), Matheus H. B. Da Silva (Em), Luccas E. d. O. Marinho (PG), Bruno Coraucci Filho (PQ)

Resumo

O sistema tanque séptico é amplamente utilizado no Brasil. Esse sistema de tratamento gera um lodo com grande potencial de ser reciclado em solos agrícolas. O objetivo desse trabalho foi o de promover o desaguamento e secagem do lodo séptico, por meio de contentores de geotêxtil e avaliar sua biodebradabilidade. Foram usados três contentores de geotêxtil de diferentes. Em todos eles, a perda média de massa foi a mesma ao final do experimento. Após o desaguamento a biodegradabilidade do lodo foi avaliada pela respirometria, estando o lodo apto a ser utilizado em solos agrícolas.
\end{abstract}

Palavras Chave: Contentores de geotêxtil, reciclagem de nutrientes, desaguamento de lodo.

\section{Introdução}

Os tanques sépticos estão presentes em $45 \%$ dos domicílios brasileiros ${ }^{[1]}$.

Uma das alternativas quanto ao desaguamento dos lodos de esgoto corresponde a sua filtração em contentores de geotêxtil. Esses são fabricados utilizando-se uma ou mais camadas de costura, as quais são apertadas de acordo com a abertura aparente que se objetiva, de acordo com a característica do material a ser desaguado. $\mathrm{Em}$ escala real pode haver uma retenção de $93,5 \%$ de sólidos e redução de volume para $20 \%$ do inicial $^{[2]}$.

Dessa forma, o objetivo desse trabalho foi de realizar o desaguamento de lodo de tanque séptico utilizando os contentores de geotêxtil e avaliar a sua reciclagem em solo agrícola.

Resultados e Discussão

O desaguamento ocorreu por um período de 120 dias, em três campanhas, onde foram avaliados três contentores de geotêxtil diferentes. Os dados obtidos estão apresentados na Tabela 01.

O teor de umidade do lodo ao final da terceira campanha variou entre $36 \%$ e $40 \%$. Essa redução demonstra que os contentores tiveram uma grande eficiência de redução de volume. Comparando-se os contentores entre si, não houve diferença significativa no tipo de contentor utilizado uma vez que todos apresentaram uma mesma eficiência de retenção de sólidos.

Tabela 01 - teores de umidade do lodo ao final do experimento

\begin{tabular}{cccc}
\hline Amostra & \multicolumn{3}{c}{ Umidade (\%) } \\
\hline & C 1 & C 2 & C 3 \\
\hline CG 1 & $45,7 \pm 8,6 a$ & $28,9 \pm 4,9 a$ & $36,2 \pm 6,9 a$ \\
CG 2 & $48,1 \pm 4,6 \mathrm{a}$ & $29,5 \pm 5,3 \mathrm{a}$ & $38,1 \pm 2,7 \mathrm{a}$ \\
CG 3 & $52,8 \pm 5,7 \mathrm{a}$ & $36,0 \pm 7,5 \mathrm{~b}$ & $40,4 \pm 6,9 \mathrm{a}$ \\
\hline
\end{tabular}

A determinação da taxa de biodegradabilidade do lodo desaguado foi realizada pelo ensaio de respirometria ${ }^{[3]}$, realizada em três taxas de aplicação, 10 ton ha ${ }^{-1} 37,2$ ton ha $^{-1}$ e 55,8 ton ha ${ }^{-1}$ (Figura 01). O porcentual de degradação da matéria orgânica alcançado para os três tratamentos foram respectivamente $80 \%, 63 \%$ e $43 \%$.

Figura 01 - Gráfico da evolução da produção de $\mathrm{CO}_{2}$ pelo teste respirométrico

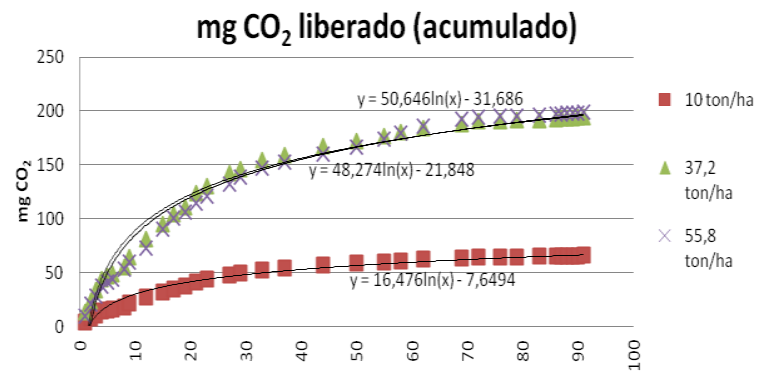

Dia

\section{Conclusões}

Os valores de umidade do lodo ao final do experimento foram similares em todos os CG utilizados e estiveram entre $36 \%$ e $40 \%$. Os CG demonstraram ser uma alternativa viável no desaguamento de lodos sépticos.

O lodo desaguado foi classificado como biodegradável pelas análises respirométricas.

\section{Agradecimentos}

\section{$\mathrm{CNPq}-\mathrm{PIBIC/EM}$}

\footnotetext{
${ }^{[1]}$ IBGE. Pesquisa nacional de saneamento básico. Rio de Janeiro: Instituto Brasileiro de Geografia e Estatística, 2010. 219pp. ${ }^{[2]}$ CANTRELL, K. B.; CHASTAIN, J. P.; MOORE, K. P. Geotextile filtration performance for lagoon sludge and liquid animal manure dewatering. American Soc. of Agricul.1 and Biol. Eng. 51(3):10671076, 2008.

${ }^{[3]}$ RODELLA, A. A.; SABOYA, L. V. Calibration for condutimetric determination of carbon dioxide. Soil Biol. Bioch., 31:2059-2060, 1999.
} 